\title{
Fleur Gabriel: Deconstructing Youth: Youth Discourses at the Limits of Sense
}

\author{
Palgrave Macmillan, 175 5th Avenue, New York, NY, 2013, 234 pp, \\ ISBN: 9780230363335
}

\author{
Jonathan M. Baker ${ }^{1}$
}

Received: 30 May 2015/Accepted: 2 June 2015/Published online: 10 June 2015

(C) Springer International Publishing 2015

Deconstructing Youth: Youth Discourses at the Limits of Sense, by Fleur Gabriel, provides a compelling analytical account of the confounding presence that youth have in modern Western culture. The book is geared towards adults seeking to better understand the youth mind. Gabriel starts with a general approach to defining what youth is and how it is viewed and translated across multiple domains (such as parental/clinical and the media). In the later chapters, Gabriel turns to a more narrowly tailored approach drawing on specific case studies that depict "youth in action" in their most controversial and feared light. This includes examples from popular films that depict teen rebellion to a discourse of the columbine school shooting massacre that occurred in 1999. The book aims to add insight into the preexisting views of how contemporary youth is thought about in modern society. More importantly the book offers guidance and presents itself as a go-to manual for adults seeking to come to terms with the most alarming of youth activities. Gabriel's approach to deconstructing youth offers compelling alternatives to the norm that are essential if the social hierarchy is to be maintained.

In chapter 1, the "Introduction", Gabriel explores the idea that the contemporary Western view of youth in society needs to be reformed. The strict binary between child and adult which mainstream society uses, according to Gabriel, is unsatisfactory. Instead, Gabriel evokes the idea that the concept of youth can stand alone as its own separate culture with its own connotations similar to how the terms adult and child are separated now. Gabriel opens the chapter with an analysis of a campaign performed in

Jonathan M. Baker

jmbaker227@gmail.com

1 Bloomington, Indiana, USA
Australia on youth "binge drinking". The campaign was staged to be similar to common campaigns performed to raise awareness about smoking and HIV/AIDS, however the advertisements were purposed with the goal to "scare the living daylights out of young people" (Gabriel 2013, p. 7). This campaign serves as a dual purpose to both scare and protect youth and elicits the idea that adolescents can be seen as a threat to society. In this chapter, Gabriel starts to disentangle some of the ambiguity behind the term youth and proposes an idea that sets the stage for the rest of the book. The idea proposed is simply thinking youth or "a focus on how youth is thought and how knowledge of youth is being constructed" (Gabriel 2013, p. 11).

Chapter 2, "The State of Contemporary Youth: Conceptual Underpinnings of Dominant Youth Discourses," develops the ideology behind what it means to be an adolescent in contemporary or "mainstream" society. Gabriel opens the chapter with a brief summary of the main points, then offers two stories centered on disturbing youth behavior in Australia. The stories revolve around two groups of teenagers committing acts of crime and deviance that question how society views its youth. Gabriel begins with the "Teenage Kings of Werribee" a video that depicts several teenage boys bullying and sexually assaulting another teenage girl with a known developmental delay. The video footage displays the boys urinating on her, setting fire to her hair, and forcing her to perform oral sex. Another video titled "Gobs 2012" featured a group of teenage girls offering, but not performing, oral sex for 80 cents per minute to supposedly raise money for the prevention of sexual assault. However, once this video went viral the original intent of the video (whatever it may have been) was lost. Gabriel claims that "this kind of behavior from young people, both boys and girls, transgresses not just social expectations concerning youth, but the perceived 
limits of youth behavior if grounded in an assumption of innocence and a limited self-awareness" (Gabriel 2013, p. 24).

Gabriel understands that normality in youth is a large understatement and uses this to his advantage while developing his working definition of youth. Gabriel introduces a myriad of prevalent researchers in the fields of psychology, developmental psychology, sociology, and philosophy to bring perspective and enlightenment on how youth are envisioned in a contemporary manner. In light of coming to terms with the highly debated subject of youth, Gabriel delivers three distinct but fluid conceptual paradigms that define youth. The paradigms include the "developmental paradigm", the "critical political economy paradigm" and the "(sub)cultural paradigm". Gabriel claims the developmental paradigm defines youth according to physiological growth and development in relationship to adult-level mental function and physical state. This is opposed to the critical political economy paradigm that defines youth as a state of being or lived experience marked according to racial, gender and class distinctions under capitalism. The (sub)cultural paradigm defines youth as a cultural category according to relationships of class, style and consumption and in terms of constructions of taste and lifestyle preferences. The argument is that the construction of these paradigms keeps us constricted in the current trends on youth discourse.

Chapter 3, "Deconstruction and the Question of Identity," aims to completely deconstruct the concept of youth by exploring the myriad of routes that gave shape to the modern viewpoints of youth identified in Chapter 2. Gabriel takes us back to the post-colonial era and investigates the "Western imperialist and its silencing of certain groups and cultures" (Gabriel 2013, p. 65). Gabriel uses the work of Edward Said to define a term known as "Orientalism," which describes a situation in which Western culture ostracized any group contrary to their general way of life. According to Said, "Orientalism represents a Western style dominating, restructuring, and having authority over the Orient, rather than a means for articulating the Orient, or the nations and cultures located in the East, as a free subject of thought or action" (Gabriel 2013, p. 65). Gabriel incorporates this idea because it parallels with many of the ways youth is thought about. The Westerner is thought of as the "model" being needing not to conform to change but instead to be looked at as concrete and definitive. Gabriel (2013, p. 67) states "this knowledge is consequently used to order social relations and discourses around youth as 'transitional', 'incomplete', 'in between', 'less than' or 'lacking' in their mental, social, and physical capacities. Therefore, making them in need of protection and guidance to ensure that they become 'adults' in the proper way and at the proper time".
Contemporary "Adult" culture mimics the view of the traditional "Western imperialist" by subordinating groups they feel threatened by, such as modern youth. Indeed, the most curious part of this chapter actually deals with the skills needed to become adult. These traditional viewpoints that dominate much of the first half of the chapter and give heed to the all prevailing adult, trigger a shift in thought. The shift from adults relies on youth to act out and rebel on social order in order for the adult to define itself. The shift is from a pure binary standpoint relying on the broad categories of child and adult. And it is a shift in a thought where adolescence is not viewed as a threat to society but a smooth transitional period where attention and guidance are imperative. It further is a transition from the thought of being able to change the confines of the category of youth from the outside. Lastly, it is a shift in thinking of youth as being an autopoietic system where change can only come from within the system.

In chapter 4, "Reasonable Unreason: The Limits of Youth in the Teen Brain", Gabriel relies heavily on a developmental psychological approach. Gabriel melds cutting edge psychological research with state of the art brain imaging technology in an attempt to decipher and possibly catch a glimpse of the internal working components that drive the mysterious youth psyche. The beginning of the chapter focuses on brain imaging performed by MRI. Gabriel (2013, p. 89) mentions a "longitudinal study conducted by Dr. Jay Giedd. Giedd has recently been able to conduct MRI scans on participants (aged 3-27) every two years building up records of their brain development and how the brain matures". The studies with MRI imaging have led researchers down new paths resulting in the mapping of "extensive structural change" of gray and white brain matter. This is a structural change that leads to prefrontal cortex development and a key process when discussing youth and the child/adult binary. The takeaway from this research is that "development, for everyone, follows a set sequence of stages that occur in the same order and at roughly the same time and that youth are in fact not fully developed in these areas" Gabriel (2013, p. 91).

The end of the chapter leads to a discussion about genes and how environmental factors shape our development. The drawback is that all of this research appears to strengthen the adult/child binary theory and mark youth as disabled members of society. It is no surprise, then, that developmental theory would make sense in light of youth being portrayed as a threat to society and being marked as debilitated members of society through the lens of adults. Gabriel (2013, p. 120) claims that "in order to keep the notion of rationality intact, the teen brain research can do no more than assert that teens behave in baffling, inconsistent ways, and confirm the 'enduring stereotype' of 
youth as a time of "turbulence, exuberance and passion". Gabriel seeks to hold on to the traditional binary thought of youth but at the same time expose its insufficiency.

Chapter 5 is entitled "Presumed Innocent: The Paradox of 'Coming of Age' and the Problem of Youth Sexuality". The beginning of the chapter frames youth in the existing mindset that "sexualization of youth is deeply offensive to a commonly held and indeed cherished belief in childhood innocence" Gabriel (2013, p. 127). Gabriel explores the sexualization of youth that naturally targets the sexualization of young females during the "coming of age" stage of development. This stage is regarded as a stage of innocence in need of preservation. Gabriel highlights that the current ideologies held about sexualization of youth are self-defeating. This notion of marking youth as a self-defeated process is the fundamental aspect of this chapter and signals that youth must be imagined differently. This process is exquisitely described by Gabriel when he claims "The discourse of 'coming of age' describes something that is supposed to happen given the values and structures of modern society, but which at the same time is prevented from happening by those very same structures" Gabriel (2013, p. 132). This idea stems from a frame of reference mentioned earlier in that "innocence is something to reverse and to seek to protect in its 'wholeness' at the same time as it must be left behind or cast off" Gabriel (2013, p. 133). In short, youth must be contemporaneous.

The later portion of Chapter 5 develops around the more eerily notion that youth do in fact have the capability of conscientiously controlling their actions and desires. Gabriel uses three movies that obtained national attention to distinguish this viewpoint, the films are titled Thirteen, Lolita and Towel head. Lolita and Towel head portray young 'tween' girls in pedophilic relationships with much older men and Thirteen depicts teenage youngsters defying their roles as youth and engaging in sex drugs and self-mutilation. In an effort to explain this behavior and move forward with the idea that these teen perplexities exist, Gabriel uses a metaphysical research of Jacques Derrida. Derrida claims that thinking in terms of binaries is insufficient to explain this behavior and proposes that we engage in a space of undecidability. Gabriel (2013, pp. 138-139)notes that if "Derrida's argument holds, this means that the metaphysical distinction made between youth and adult on the basis of innocence/knowledge as it applies to sexuality cannot remain intact. This opposition cannot account for a stage that is 'becoming'; a stage that is based neither in innocence nor in knowledge, or that is both these things at the same time, and is therefore "undecidable"'. The work of Derrida and idea of engaging in undecidability marks an important transition in Gabriel's working definition of youth. It removes the constraints that binaries hold on the traditional ways of thinking about youth and opens up new outlooks.
Even outlooks that are socially and morally closed and Derrida claims "In this instance, that means risking what seems an irresponsible choice: that paedophilia is not wrong" (Gabriel, 2013, p. 144).

Chapter 5 and chapter 6 are "cut from the same cloth," however, chapter 5 deals with youth girls and sexuality and in chapter 6, "Normal Abnormality: Coming to Terms with Teen Violence and the Undecidability of Youth," Gabriel discusses youth boys and their alarming acts of violence. Gabriel opens the chapter by focusing on the phenomenon of school shootings and, in particular the 1999 Columbine massacre. Gabriel chose this particular case to strengthen the argument raised in chapter 5 , that in order to come to terms with tragic events such as school shootings and paedophilia the metaphysical approach of "undecidability" must be adopted. This adoption of undecidability marks the conclusion to Gabriel's definition of youth. This is foreshadowed when Gabriel claims that "searching questions have been asked about the perpetrators' psychology, their upbringing and social environment, their media influences, and their school and peer culture to try and understand their intentions" (Gabriel, 2013, p. 162). Gabriel goes on to state that his own interest in the Columbine case is indeed the fact that it "defied adequate explanation, many explanations for the tragedy are grounded in the context of the two shooters' youth and as such operate from a developmental discourse as conditioned by a presence/absence binary split" (Gabriel, 2013, p. 162). There is still no logical explanation for why the Columbine massacre occurred. However, if Gabriel's approach to youth can be embraced, there is no need for a logical explanation to move forward. Gabriel claims "there is nothing else to do here but mark the singularity of this event as being beyond explanation, so referring back to the work on the discourse of sublime. It is better to treat the event itself as beyond our ability to interpret it, to know what it means. In other words, as a form of response, or rather a form of non-response, it is better to affirm a Romantic inexplicability" (Gabriel, 2013, p. 189).

Overall, Gabriel's work makes a significant contribution to the study of adolescence. Each chapter introduces highly debated topics surrounding the uncertain, undefinable identity of today's modern youth. It would appear that modern adult culture has seemingly reached a dead end when an attempt is made to theorize or conclude issues dealing with deviant youth behavior. Gabriel is able to use the roots already grounded from past ideologies about youth discourse and shed new light on an ostensibly over used topic. Gabriel does this by integrating a strong metaphysical approach into developmental psychology. The contribution is significant because Gabriel is able to shift us from a one dimensional, almost stagnant state of thought about youth to a multidimensional, transgressed 
thought that is full of hope and potential. The book does a fantastic job of trying to make sense of a very complicated subject matter. It achieves this by presenting some of the most distraught cases of youthful behavior and systematically deconstructing them through the viewpoints of multiple scholars across all genre of academia in order to achieve a scientific means to an end. And after pages of endless controversy, Gabriel leads us to a bittersweet ending in which he implies we will forever be stuck in the perils of youth inexplicability and undecidability. It is, therefore, imperative to acquire a strong sense of resilience and reflexivity in future dealings with youth because
Gabriel has shown that the contested concept of youth will never be resolved and that youth discourses will never be resolved by scientific facts.

Conflict of interest None.

\section{Reference}

Gabriel, F. (2013). Deconstructing youth: Youth discourses at the limits of sense. New York, NY: Palgrave Macmillan. 